\title{
A socio-demographic study of aging in the Portuguese population: The EPEPP study
}

\author{
Anabela Mota-Pinto ${ }^{\mathrm{a}, *}$, Vítor Rodrigues ${ }^{\mathrm{a}}$, Amália Botelho ${ }^{\mathrm{b}}$, Manuel Teixeira Veríssimo ${ }^{\mathrm{a}}$, \\ António Morais ${ }^{a}$, Catarina Alves ${ }^{c}$, Manuel Santos Rosa ${ }^{a}$, Catarina Resende de Oliveira ${ }^{a}$ \\ ${ }^{a}$ Faculty of Medicine, University of Coimbra, Rua Larga, 3004-504 Coimbra, Portugal \\ ${ }^{\mathrm{b}}$ Faculty of Medical Sciences, New University of Lisbon, Campo dos Mártires da Pátria, no. 130, 1169-056 Lisboa, Portugal \\ ${ }^{\mathrm{c}}$ Eurotrials, Consultores Científicos, Rua Tierno Galvan, Torre 3, Piso 16. 1070-274 Lisboa, Portugal
}

\section{A R T I C L E I N F O}

\section{Article history:}

Received 5 January 2010

Received in revised form 16 April 2010

Accepted 20 April 2010

\section{Keywords:}

Population aging

Social network

Social isolation

Education and aging

\begin{abstract}
A B S T R A C T
The increase in life expectancy (LE) observed in Western societies, has resulted in a steep rise of older population. This stresses the importance of the research on aging, to better adequate health and social care organization and improve the quality of life $(\mathrm{QoL})$. The aim of the EPEPP- 1 (abbreviated from the Portuguese name: Estudo do Perfil de Envelhecimento da População Portuguesa) study was to characterize the socio-demographic components of the elderly Portuguese population in order to disclose factors that could play a role in the aging process and in the elderly QoL. This observational descriptive study, was performed in 2672 individuals older than 54 years taking into account gender and the residence area (rural vs. urban). A questionnaire about social network (marital status, living alone, the hours spent alone, confidents), and social status (education, occupation) was applied. Social network score revealed significant age and gender trends, women and older people performing worst, but with no difference according to residence area. Almost a third was unmarried and spent eight or more hours per day alone, and a fifth lived alone. Social status revealed that being older female and resident in a rural area quoted worst in the prevalence of illiteracy and undifferentiated occupation. The authors concluded that social isolation, illiteracy and undifferentiated occupation are prevalent in Portuguese older population. Identification of further determinants of isolation, adjustment of procedures to be included in social networks and development of actions directed to education are important fields of intervention influencing the elderly QoL.
\end{abstract}

(c) 2010 Elsevier Ireland Ltd. All rights reserved.

\section{Introduction}

The increase in LE observed worldwide led to a subsequent increase in aged population, which occurred mainly in industrialized countries at the end of the XXth century. In Europe, older people represented $15 \%$ of the total population in $1971,20 \%$ in 2000 , and it is expected to reach as much as 35\% by 2050 (Mirkin and Weinberg, 2001; Christensen et al., 2009). In Portugal, this prevalence ranged from $8 \%$ in 1960 to $17 \%$ in 2007 and projections to the year 2050 suggest an increase to $32 \%$ (INE, 2003 , 2008). So profound is this demographic revolution that every aspect of social life and society is being affected. The current level and way of population aging vary widely by geographic region, and within regions. Family structure has undergone great changes, moving from the multi-generational

\footnotetext{
* Corresponding author at: Faculty of Medicine, University of Coimbra, Rua Larga, 3004-504 Coimbra, Portugal. Tel.: +351 23982 2547; fax: +3512 39822547.

E-mail address: apinto@fmed.uc.pt (A. Mota-Pinto).
}

structure to the more individualistic nuclear family with no traditional family support system. As individuals live longer, the quality of that longer life becomes a central issue for both personal and social well being. The steep rise of elderly populations poses challenges to social institutions that must be adapted to changing age structures. Discrepancies between the trends in social network and social status must be characterized (Rohr and Lang, 2009).

Area of residence is strongly related with industrialization, culture, education, occupation and economic status (Golant, 2003; Marcellini et al., 2007), being an important determinant on social networking.

Education is also a key factor on the wellness and social status. Strongly related with occupation and income, it influences house conditions, QoL and coping, less educated people being more prone to economic and social threats (Litwin, 2003; Hawkley et al., 2008). The level of education has been identified as a potentially powerful factor influencing disability, in the sense that higher levels of education usually translate into better health status (Kevin and Velkoff, 2001). 
The aim of the EPEPP study was to characterize a representative sample of Portuguese individuals aged 54 and over. We focus the present analysis on social network and social status taking into account the age group, the gender and area of residence (urban vs. rural), in order to disclose factors that could play a role in the aging process and in the elderly QoL.

\section{Subjects and methods}

\subsection{Subjects}

An observational study, community-based, from a representative sample of the Portuguese population older than 54 years was conducted, involving 26 randomly selected health centers. It was carried out from December 2005 to April 2006, under the coordination of the Faculty of Medicine of Coimbra University and the support of the Regional Health Administration.

Participants were randomly selected through national telephone directories and stratified by age group (55-64, 65-74 and $>75$ years old), gender, and area of residence (urban, rural). The definition of area of residence was done according to population density of Portuguese mainland (INE, 2004).

People were recruited by telephone and anonymity procedures have been taken. Inclusion criteria were defined by the ability to go to the local health centre and to perform verbal communication. In order to obtain a maximum error of $2 \%$ with a $95 \%$ confidence interval, the sample survey was calculated to be of 2516 individuals.

A comprehensive questionnaire evaluation, conducted by trained interviewers was previously validated in the Portuguese population (Botelho, 2000). The focus of this study was the evaluation of the social network (marital status, living alone, hours spent alone, having confidents) and social status (school frequency/ number of years of formal education, occupation) of the Portuguese population with 54 years and over. Scores for social network were calculated by summing up the quotations of its components, according to criteria explored in a previous study (Botelho, 2000).

\subsection{Statistical analysis}

The Statistical Package for Social Sciences (SPSS) v.15 performed statistical analysis. Frequency distribution and chisquare were computed to assess differences between gender and age group, and gender and area of residence, in each item. Analysis of variance (ANOVA) was performed to study differences in the number of education years between gender and area of residence. Logistic regression was performed considering "hours alone" as a dependent variable and as independent variables: age group (55$64,>65$ ), gender (female, male), area of residence (urban, rural), marital status (married, not married), living alone (yes, no), having confidents (no, yes) and education ( $0-6,>7$ school years). Values of $p<0.05$ were considered statistically significant.

\section{Results}

A total of 2672 subjects (1139 men and 2672 women) were studied. This population was divided into three age groups: $39 \%$ with $55-64$ years, $37 \%$ with $65-74$ years and $24 \%$ with $\geq 75$ years old. Sixty percent of the subjects were living in urban areas and $40 \%$ in rural areas. The presence of "no answer" across items was below $1 \%$, except in "years of education" where it ranged $8 \%$.

Focusing on social network (Tables 1 and 2) 29\% of the individuals were unmarried, particularly in the older age groups

Table 1

Sample characteristics by age group within gender.

\begin{tabular}{|c|c|c|c|c|c|c|c|}
\hline \multirow[t]{2}{*}{ Parameters } & \multicolumn{3}{|l|}{ Male } & \multicolumn{3}{|l|}{ Female } & \multirow[b]{2}{*}{$p$} \\
\hline & $55-64$ & $65-74$ & $>75$ & $55-64$ & $65-74$ & $>75$ & \\
\hline \multicolumn{8}{|c|}{ Marital status (\%) } \\
\hline Widow & 1.8 & 6.2 & 14.0 & 12.3 & 29.5 & 55.2 & ns \\
\hline Sep/divorced & 3.6 & 2.1 & 3.3 & 6.3 & 4.5 & 1.4 & $<0.05$ \\
\hline Single & 3.6 & 3.6 & 3.3 & 4.9 & 3.9 & 10.7 & $<0.05$ \\
\hline Married & 91.1 & 88.1 & 79.4 & 76.5 & 62.1 & 32.6 & $<0.001$ \\
\hline \multicolumn{8}{|l|}{ Lives with (\%) } \\
\hline Alone & 5.9 & 4.9 & 9.7 & 13.4 & 25.9 & 47.4 & $<0.01$ \\
\hline Spouse & 90.9 & 88.8 & 79.1 & 75.4 & 61.6 & 31.5 & ns \\
\hline $\operatorname{Sun}(s)$ & 1.1 & 2.4 & 4.1 & 7.2 & 10.1 & 14.4 & ns \\
\hline Parents & 0.5 & 0.2 & 0.7 & 2.4 & 0.2 & 0.2 & ns \\
\hline Other & 1.6 & 3.7 & 6.3 & 1.7 & 2.2 & 6.5 & \\
\hline \multicolumn{8}{|c|}{ Hours spent alone (\%) } \\
\hline$\geq 8 \mathrm{~h}$ & 26.5 & 25.8 & 26.4 & 35.8 & 40.4 & 46.8 & $<0.05$ \\
\hline$\leq 8 \mathrm{~h}$ & 73.5 & 74.2 & 73.6 & 64.2 & 59.6 & 53.2 & ns \\
\hline \multicolumn{8}{|c|}{ To have confidents (\%) } \\
\hline No & 6.5 & 6.0 & 7.7 & 8.2 & 10.2 & 8.6 & ns \\
\hline Yes & 93.5 & 94.0 & 92.3 & 91.8 & 89.8 & 91.4 & $<0.05$ \\
\hline \multicolumn{8}{|c|}{ Social network score (\%) } \\
\hline$<2$ & 8.8 & 9.8 & 13.0 & 18.5 & 31.7 & 54.3 & $<0.01$ \\
\hline$>2$ & 91.2 & 90.2 & 87.0 & 81.5 & 68.3 & 45.7 & ns \\
\hline \multicolumn{8}{|c|}{ School frequency (\%) } \\
\hline No & 4.7 & 11.0 & 4.9 & 2.1 & 11.3 & 21.1 & $<0.0001$ \\
\hline Yes & 95.3 & 89.0 & 95.1 & 97.9 & 88.7 & 78.9 & $<0.0001$ \\
\hline \multicolumn{8}{|c|}{ Years of education (\%) } \\
\hline Mean & 5.69 & 4.24 & 5.06 & 5.5 & 4.7 & 5.06 & \\
\hline$\pm \mathrm{SD}$ & 3.98 & 2.82 & 3.63 & 3.7 & 3.6 & 3.63 & \\
\hline \multicolumn{8}{|l|}{ Occupation (\%) } \\
\hline Lower differ. & 87.7 & 87.2 & 86.2 & 86.3 & 91.7 & 92.1 & $<0.05$ \\
\hline Higher differ. & 12.3 & 12.8 & 13.8 & 13.7 & 8.3 & 7.9 & ns \\
\hline
\end{tabular}

Notes: ns, not significant. 
Table 2

Sample characteristics by gender and area of residence.

\begin{tabular}{|c|c|c|c|c|c|c|c|c|}
\hline & \multicolumn{4}{|c|}{ Gender } & \multicolumn{4}{|c|}{ Area of residence } \\
\hline & Male & Female & Total & $p<$ & Urban & Rural & Total & $p<$ \\
\hline \multicolumn{9}{|l|}{ Marital status (\%) } \\
\hline Widow & 6.3 & 30.4 & 20.1 & 0.001 & 20.3 & 19.9 & 20.1 & ns \\
\hline Separated/divorced & 3.5 & 6.1 & 5.0 & & 5.2 & 4.7 & 5.0 & \\
\hline Single & 3.0 & 4.3 & 3.7 & & 4.0 & 3.3 & 3.7 & \\
\hline Married & 87.2 & 59.2 & 71.1 & & 70.5 & 72.0 & 71.1 & \\
\hline \multicolumn{9}{|l|}{ Lives with (\%) } \\
\hline Alone & 6.5 & 27.3 & 18.5 & 0.001 & 19.1 & 17.5 & 18.5 & ns \\
\hline Spouse & 87.3 & 58.3 & 70.6 & & 69.9 & 71.6 & 70.6 & \\
\hline Son(s) & 2.3 & 3.2 & 2.8 & & 7.3 & 6.3 & 6.9 & \\
\hline Parents & 0.4 & 10.2 & 6.1 & & 0.8 & 0.8 & 0.8 & \\
\hline Other & 3.5 & 1.0 & 2.1 & & 2.9 & 3.9 & 3.3 & \\
\hline \multicolumn{9}{|l|}{ Hours spent alone (\%) } \\
\hline$>8 \mathrm{~h}$ & 26.2 & 40.5 & 34.4 & 0.001 & 35.3 & 33.1 & 34.4 & ns \\
\hline$<8 \mathrm{~h}$ & 73.8 & 59.5 & 65.6 & & 64.7 & 66.9 & 65.6 & \\
\hline \multicolumn{9}{|l|}{ To have confidents (\%) } \\
\hline No & 6.6 & 9.0 & 8.0 & 0.05 & 7.5 & 8.6 & 8.0 & ns \\
\hline Yes & 93.4 & 91.0 & 92.0 & & 92.5 & 91.4 & 92.0 & \\
\hline \multicolumn{9}{|c|}{ Social network score (\%) } \\
\hline Unfavorable $<2$ & 10.6 & 34.5 & 24.3 & 0.001 & 25.3 & 22.8 & 24.3 & ns \\
\hline Favorable $>2$ & 89.4 & 65.5 & 75.7 & & 74.7 & 77.2 & 75.7 & \\
\hline \multicolumn{9}{|l|}{ School frequency (\%) } \\
\hline No & 4.9 & 10.5 & 8.0 & 0.0001 & 5.9 & 11.0 & 7.9 & 0.0001 \\
\hline Yes & 95.1 & 89.5 & 92.0 & & 94.1 & 89.0 & 92.1 & \\
\hline \multicolumn{9}{|l|}{ Years of education (\%) } \\
\hline Mean & 5.5 & 4.7 & 5.06 & 0.0001 & 5.69 & 4.24 & 5.06 & 0.0001 \\
\hline SD & 3.7 & 3.6 & 3.63 & & 3.98 & 2.82 & 3.63 & \\
\hline \multicolumn{9}{|l|}{ Occupation (\%) } \\
\hline Lower differ. & 87.2 & 89.8 & 88.6 & $<0.05$ & 85.6 & 92.0 & 88.2 & 0.001 \\
\hline Higher differ. & 12.8 & 10.2 & 11.4 & & 14.4 & 8.0 & 11.8 & \\
\hline
\end{tabular}

( $p<0.01$ ): $27 \%$ ( $65-74$ years old) $49 \%$ ( $\geq 75$ years old) $v s .17 \%$ in the range of $55-64$ years old. From the unmarried group $41 \%$ were female ( $p<0.01$ ) 30\% being widows. Considering age and gender, the decline in married status markedly increased in female from $77 \%$ ( $55-64$ years) to $33 \%$ ( $\geq 75$ years old) when comparing to male, $91 \%$ vs. $79 \%$, respectively. The analysis of the residential area showed that the prevalence of married (71-72\%) and widowed (20\%) subjects was similar in both rural and urban areas. Nineteen percent of the individuals were living alone (7\% men and $27 \%$ women) being more older female (47\%) than male $(10 \%)(p<0.01)$, with no influence of the area of residence (18-19\%). The analysis of the number of hours spent alone revealed that $34 \%$ of the individuals spent eight or more hours per day alone: $39 \%$ from the older age group ( $\geq 75$ years), 34\% (65-74 years) and 32\% (55-64 years) $(p=0.01)$. It was also observed that $41 \%$ of women spent eight or more hours per day alone comparing to men (26\%) $(p<0.001)$. Time spent alone increased with age in female and remained stable in male $(p<0.05)$. This variable had no influence of area of residence (33-35\%). Not having a confident was similar among age groups, but not between women (9\%) and men (7\%) $(p<0.05)$, being different according to age and gender, mainly in the age group of 65-74 years old. This item was not influenced by area of residence (8-9\%).

In accordance with the above data, the social network score had no influence of area of residence and revealed age and gender trends ( $p<0.01$ ), with an unfavorable result in 35\% female vs. $11 \%$ male, raising with age in women: 19\% (55-64 years old), 32\% (6574 years old) and $54 \%$ ( $\geq 75$ years old) as compared to men $(9 \%, 10 \%$ and $13 \%$, respectively).

The item social status was assessed by school frequency, years of formal education and occupation. We observed that $92 \%$ of the individuals had school frequency. Illiteracy revealed age and gender trends $(<0.0001)$ particularly in the oldest women $(21 \%)$, being also markedly different according to area of residence $(p<0.0001)$, almost the double in rural $(11 \%)$ than in urban populations (6\%). Considering occupation, undifferentiated occupation $(89 \%)$ was more prevalent $(<0.05)$ in the oldest women (92\%), and in rural $(92 \%)$ than in urban $(86 \%)$ areas $(p<0.001)$ (Tables 1 and 2).

A multiple variable analysis was performed to evaluate the relevance of studied variables in older people isolation, referred as being alone eight or more hours a day (Table 3). A logistic regression model showed that female gender (odds ratio $=\mathrm{OR}$ $=1.36 ; 1.12-1.64)$, unmarried marital status $(\mathrm{OR}=1.4 ; 1.06-1.85)$ and living alone (OR: $4.13 ; 3.00-5.68)$ were associated with social isolation.

\section{Discussion}

This report is focused in socio-demographic aspects as part of an exhaustive study on the aging patterns of the Portuguese population. EPEPP study is the first survey of socio-demographic

Table 3

Risk of being alone eight or more hours a day.

\begin{tabular}{lll}
\hline Variable & OR $(95 \% \mathrm{CI})$ & $p<$ \\
\hline Constant & & 0.000 \\
Area of residence (urban) & $1.08(0.90-1.30)$ & 0.412 \\
Gender (female) & $1.36(1.12-1.64)$ & 0.002 \\
Age $(\geq 65$ years) & $0.85(0.71-1.03)$ & 0.101 \\
Marital status (not married) & $1.4(1.06-1.85)$ & 0.018 \\
Living alone (yes) & $4.13(3.00-5.68)$ & 0.0001 \\
Having confidents (no) & $0.96(0.69-1.33)$ & 0.804 \\
Education (0-6 school years) & $0.98(0.78-1.22)$ & 0.825 \\
\hline
\end{tabular}


parameters (social network and social status) conducted in the elderly in Portugal. The applied coordination, sampling, recruitment, administration of the questionnaire and grouping of participants for analysis seemed quite adequate.

The analysis of the social network variables demonstrated that marital status is a key indicator and a predictor of isolation. Age and gender analysis showed to be related to married or widowhood civil status, women having a higher longevity and rate of widowhood. This is in agreement with higher LE of women, which were 85.2 years in female and 81.6 years in male in Portugal in 2007 (INE, 2008). Also the frequency of marriage in widowed older men doubles as compared to women. It has also been reported that women of the same age group tend to live alone when comparing to men, almost five times more in the two older age groups in developed countries (Kevin and Velkoff, 2001).

In the same sense, we observed that being alone eight or more hours per day was related to age and gender. Women spend many hours alone, with a prevalence that increases with aging, probably contributing to isolation and loneliness. In contrast only one in four elderly men spent eight or more hours per day alone. The relevance of hours spent alone on people isolation was also analyzed by other investigators, which reported a similar association of unfavorable results (Younga et al., 2004; Tomaka et al., 2006).

In what concerns the variable confidents, no difference was found in not having confidents when comparing age and gender simultaneously. In contrast men tend to have a slightly better result across age groups, particularly if they have someone to talk with, which is probably related to their higher rate on married civil status. These findings were in accordance with other studies (Freedman et al., 2008).

Area of residence did not play an important role on the social network variables, namely marital status, living alone, time spent alone and confidents as it could be expected from other studies (Lucchetti et al., 2008).

The social network score highlighted more unfavorable results for women across all age groups, independently of their area of residence, being present in a third of the total number of women, reaching more than a half of the oldest ones. A similar analysis in men showed a prevalence of near one in ten, slightly higher in the oldest. This score previously validated for the Portuguese older population was appropriate for identifying social vulnerabilities in aging.

Several lines of research have shown that higher levels of education usually translate into better health status, higher incomes, and consequently higher standards of living (Adams and White, 2004). Education significantly affects how effectively people utilize health care, also leading to limited use of technological innovation and devices that can increase interaction with society and QoL (Marcellini et al., 2000). This study demonstrated that Portuguese population still has a percentage of individuals with no school frequency, the mean of years of education being 5 years. Marked differences in illiteracy were observed according to age and gender, with double prevalence in women when compared to men, which increased from the younger to the older age groups. Older men have higher average levels of education than do older women in accordance with the data of other studies, that is gender differences in educational attainment are much smaller for younger than older cohorts (Liliane, 2005).

The quality and quantity of rural educational facilities in most nations tend to be inferior to those in urban areas. Consequently, literacy levels and educational attainment are lower in rural areas, particularly in developing countries (Kevin and Velkoff, 2001). We found double prevalence of illiteracy in rural when compared to urban areas. Also, low educational schooling influenced the type of occupation in the older Portuguese population. It is evident the association of advanced age, female gender and rural residence to less differentiated past jobs, in the same way as literacy. This is in accordance with other similar studies (Kevin and Velkoff, 2001) although this pattern is changing with the reinforcement of schooling at national level.

\section{Conclusions}

Social isolation attains a third of Portuguese older people. The multivariable analysis of determinants of social isolation, quoted by being alone eight or more hours a day, showed the enormous influence of living alone, particularly in women and in unmarried civil status.

The observed prevalence of illiteracy and less differentiated occupations, especially in the oldest, in women and in rural areas, is certainly reflected in the quality of aging.

The relevance of the present data is its national representativeness, based on a solid and comparable methodology. Notwithstanding, a broader and still precise definition of isolation, its relation to loneliness and the assessment of possible common indicators would be an interesting line of research. Actions directed to education are needed, despite the progress achieved in recent years.

The identification of the determinants and signs, in order to adjust procedures and implement adequate intervention in informal and formal social networks, is an important area of intervention.

Finally, according to demographic studies we can conclude that our global population is aging and with different patterns of living arrangements. These changes can affect life satisfaction, QoL and most importantly health and poses a myriad of challenges and new demands in social support and network that must be adapted to the shifts in population age structure.

\section{Conflict of interest statement}

\section{None.}

\section{Acknowledgements}

We thank to EUROTRIALS for implementing and conducting the project and to Regional Health Administrations for the cooperation in the study. This study was supported by a grant from Saúde XXI Programa Operacional da Saúde (Ministry of Health).

\section{References}

Adams, J.M., White, M., 2004. Biological ageing. A fundamental, biological link between socio-economic status and health? Eur. J. Public Health 14, 331-334.

Botelho, M.A., 2000. Autonomia Funcional em Idosos. Caracterização multidi-mensional em idosos utentes de um centro de saúde urbano. Laboratórios Bial, Porto (in Portuguese).

Christensen, K., Doblhammer, G., Rau, R., Vaupel, J.W., 2009. Ageing populations: the challenges ahead. Lancet 374, 1196-1208.

Freedman, V.A., Grafova, I.B., Schoeni, R.F., Rogowski, J., 2008. Neighborhoods and disability in later life. Soc. Sci. Med. 66, 2253-2267.

Golant, S.M., 2003. The urban-rural distinction in gerontology: an update of research. In: Wahl, H.W., Scheidt, R.J., Windley, P.G. (Eds.), Annual Review of Gerontology and Geriatrics, Aging in Context: Socio-Physical Environments. vol. 23. Springer, New York, pp. 280-312.

Hawkley, L.C., Hughes, M.E., Waite, L.J., Masi, C.M., Thisted, R.A., Cacioppo, J.T., 2008 From social structural factors to perceptions of relationship quality and loneliness: the Chicago health, aging, and social relations study. J. Gerontol. B: Psychol. Sci. Soc. Sci. 63, S375-S384.

INE (Instituto Nacional de Estatística), 2003. Resident Population Projections 20002050 (Portugal). INE, Lisbon, Portugal (in Portuguese).

INE (Instituto Nacional de Estatística), 2004. Estudo sobre o poder de compra concelhio (Portugal). INE, Lisbon, Portugal (in Portuguese).

INE (Instituto Nacional de Estatística), 2008. Estatísticas Demográficas 2007 [Demographic Statistics 2007] (Portugal). INE, Lisbon, Portugal (in Portuguese).

Kevin, K., Velkoff, V.A., 2001. U.S. Census Bureau, Series P95/01-1, An Aging World: 2001. U.S. Government Printing Office, Washington, D.C. 
Liliane, R., 2005. The well-being of aging people living in their own homes. J. Environ. Psychol. 25, 231-243.

Litwin, H., 2003. The association of disability, sociodemographic background, and social network type in later life. J. Aging Health 15, 391-408.

Lucchetti, M., Corsonello, A., Gattaceca, R., 2008. Environmental and social determinants of aging perception in metropolitan and rural areas of Southern Italy. Arch. Gerontol. Geriatr. 46, 349-357.

Marcellini, F., Mollenkopf, H., Spazzafumo, L., Ruoppila, I., 2000. Acceptance and use of technological solutions by the elderly in the outdoor environment: findings from a European survey. Z. Gerontol. Geriatr. 33, 169-177.

Marcellini, F., Giuli, C., Gagliardi, C., Papa, R., 2007. Aging in Italy: urban-rural differences. Arch. Gerontol. Geriatr. 44, 243-260.
Mirkin, B., Weinberg, M.B., 2001. The demography of population ageing. In: United Nations: Living Arrangements of Older Persons: Critical Issues and Policy Responses, Population Bulletin of the UN, New York, pp. 3753.

Rohr, M.K., Lang, F.R., 2009. Aging well together: a mini-review. Gerontol. 55, 333 343.

Tomaka, J., Thompson, S., Palacios, R., 2006. The relation of social isolation, loneliness, and social support to disease outcomes among the elderly. J. Aging Health $18,359-384$.

Younga, A.F., Russellb, A., Jennifer, R., 2004. The sense of belonging to a neighbourhood: can it be measured and is it related to health and well being in older women? Soc. Sci. Med. 59, 2627-2637. 